\section{(1) \\ CrossMark}

\title{
Pulmonary arterial hypertension registries: past, present and into the future
}

\author{
Jason Weatherald $\mathbb{1}^{1,2}$, Abílio Reis $\mathbb{1}^{3}$, Olivier Sitbon $\mathbb{1}^{4,5,6}$ and \\ Marc Humbert $\mathbb{1}^{4,5,6}$
}

\begin{abstract}
Affiliations: ${ }^{1}$ Dept of Medicine, Division of Respiratory Medicine, University of Calgary, Calgary, AB, Canada. ${ }^{2}$ Libin Cardiovascular Institute of Alberta, Calgary, AB, Canada. ${ }^{3}$ Pulmonary Vascular Disease Unit, Medicine Dept, Centro Hospitalar Universitário do Porto, Hospital de Santo António, Porto, Portugal. ${ }^{4}$ Université ParisSud, Faculté de Médecine, Université Paris-Saclay, Le Kremlin-Bicêtre, France. ${ }^{5}$ Service de Pneumologie, Hôpital Bicêtre, AP-HP, Le Kremlin-Bicêtre, France. 'INSERM UMR S 999, Hôpital Marie Lannelongue, Le Plessis Robinson, France.
\end{abstract}

Correspondence: Jason Weatherald, University of Calgary, Cumming School of Medicine, Dept of Medicine, Division of Respirology, Peter Lougheed Centre, 350016 Ave NE, Calgary, Alberta, T1Y 6J4, Canada. E-mail: jcweatheducalgary.ca

@ERSpublications

Registries have greatly contributed to knowledge about PAH epidemiology, risk factors, prognosis and treatment. Future registries face unique challenges but may benefit from integration of multiple data sources and capitalising on "Big Data" opportunities. http://bit.ly/2OBpapG

Cite this article as: Weatherald J, Reis A, Sitbon O, et al. Pulmonary arterial hypertension registries: past, present and into the future. Eur Respir Rev 2019; 28: 190128 [https://doi.org/10.1183/16000617.0128-2019].

Disease registries are important sources of real-world evidence that inform clinical practice and health policy, particularly when randomised controlled trials do not exist [1]. Much of what we know today about pulmonary arterial hypertension (PAH) has come from observational studies from national and/or international disease registries.

In this issue of the European Respiratory Review, SwINNEN et al. [2] provide a concise and comprehensive overview of how various registries have contributed to the current and evolving state of knowledge on PAH. They illustrate some of the major successes of modern PAH registries, which have broadened our understanding of changing patient demographics, epidemiology, natural history, risk factors and prognosis in PAH. Despite their inherent limitations, registry data continue to influence clinical practice and treatment guidelines. For example, the most recent PAH treatment algorithm in the 2018 World Symposium on Pulmonary Hypertension [3] proposes a risk-based approach to therapy, based largely on independent validation of risk assessment strategies from European and US PAH registries [4-8]. Another example of the influence of registry data on clinical care is the common use of initial triple combination therapy with an intravenous prostacyclin, an endothelin receptor antagonist and a phosphodiesterase type 5 inhibitor for patients with high risk $\mathrm{PAH}$, which comes from registry studies showing improved outcomes in treated patients [9], despite an absence of randomised controlled study data to support this practice.

Importantly, SwINNEN et al. [2] highlight the differences between current and past PAH registries, and the methodological limitations inherent to registry-based study designs. However, there are many remaining questions about PAH that can likely only be addressed in the setting of large patient registries. The

Provenance: Commissioned article, peer reviewed.

Received: 26 Sept 2019 | Accepted after revision: 03 Oct 2019

Copyright CERS 2019. This article is open access and distributed under the terms of the Creative Commons Attribution Non-Commercial Licence 4.0. 
authors provide insightful perspective on future opportunities for PAH registries in the present era of "Big Data". For rare diseases like PAH, there is enormous potential for future registries in terms of larger numbers of well-characterised patients across the globe with linkage to other data sources, such as health administrative data or biobanks. Such large scale, multinational initiatives could help us better understand aspects of PAH such as health resource utilisation in the real-world, geographic or sociocultural gaps in diagnosis or treatment, or the link between pharmacogenomic differences in populations and long-term outcomes. Other opportunities include the potential to integrate validated patient-reported data from mobile devices and digital health data or physical activity tracking apps with PAH registries. The authors also correctly note that future registries would be more useful if they use common data elements to permit sharing between countries and organisations, fostering collaboration and multinational research. The European Respiratory Society has supported several lung disease registries including the PHAROS (severe Pulmonary Hypertension mAnagement acROSs europe) Clinical Research Collaboration, which was launched in February 2019 (www.ersnet.org/research/clinical-research-collaborations). PHAROS will establish a platform for clinical research in pulmonary hypertension, in close collaboration with the European Reference Network (ERN)-LUNG [10]. During the selection process of the healthcare providers participating in the ERN-LUNG, essential information about the clinical and scientific expertise and infrastructure across Europe has been gathered. As part of the ERN-LUNG objectives, an inventory of existing national and local pulmonary hypertension registries has also been performed and interoperability to exchange data is under further evaluation. Coordination of existing and future European pulmonary hypertension registries is one of the key specific aims of PHAROS.

However, with large-scale international registry initiatives, database linkage, integration of patient-level digital mobile technology and data sharing come serious and legitimate concerns about data ownership and privacy. Data is now a valuable commodity, equally so for health data. Big Data offers great power, and with great power comes great responsibility. Recent global events, such as the Cambridge Analytica scandal, mobile data breaches and patient concerns over data security may further tighten regulations on sharing medical information to such an extent that future multinational registry initiatives are constrained to the point of being unfeasible. As clinicians and researchers participating in PAH registries, we have the dual responsibilities of advancing knowledge with the aim of improving care and outcomes, whilst ensuring patient privacy and confidentiality of data. The latter may be a major challenge, but one worth our efforts given the enormous potential of integrating new technologies and data sources into future PAH registries.

Conflict of interest: J. Weatherald reports grants, personal fees and non-financial support from Janssen Inc. and Actelion, personal fees and non-financial support from Bayer, personal fees from Novartis, and grants from Alberta Lung Association, Canadian Vascular Network, European Respiratory Society and Canadian Thoracic Society, outside the submitted work. A. Reis reports grants, personal fees and non-financial support from Janssen Inc. and Actelion, outside the submitted work. O. Sitbon reports grants, personal fees and non-financial support from Actelion Pharmaceuticals, Bayer and Merck, grants from GlaxoSmithKline, grants, and personal fees from United Therapeutics and Gossamer Bio, outside the submitted work. M. Humbert reports personal fees from Actelion and Merck, and grants and personal fees from Bayer, GSK and United Therapeutics, outside the submitted work.

\section{References}

1 U.S. Food \& Drug Administration. Real-World Evidence. www.fda.gov/science-research/science-and-researchspecial-topics/real-world-evidence Date last updated: 05 September 2019. Date last accessed: 17 September 2019.

2 Swinnen K, Quarck R, Godinas L, et al. Learning from registries in pulmonary arterial hypertension: pitfalls and Recommendations. Eur Respir Rev 2019; 28: 190050.

3 Galiè N, Channick RN, Frantz RP, et al. Risk stratification and medical therapy of pulmonary arterial hypertension. Eur Respir J 2019; 53: 1801889.

4 Hoeper MM, Kramer T, Pan Z, et al. Mortality in pulmonary arterial hypertension: prediction by the 2015 European pulmonary hypertension guidelines risk stratification model. Eur Respir J 2017; 50: 1700740.

5 Boucly A, Weatherald J, Savale L, et al. Risk assessment, prognosis and guideline implementation in pulmonary arterial hypertension. Eur Respir J 2017; 50: 1700889.

6 Kylhammar D, Kjellström B, Hjalmarsson C, et al. A comprehensive risk stratification at early follow-up determines prognosis in pulmonary arterial hypertension. Eur Heart J 2018; 39: 4175-4181.

7 Weatherald J, Boucly A, Launay D, et al. Haemodynamics and serial risk assessment in systemic sclerosis associated pulmonary arterial hypertension. Eur Respir J 2018; 52: 1800678.

8 Benza RL, Gomberg-Maitland M, Miller DP, et al. The REVEAL Registry risk score calculator in patients newly diagnosed with pulmonary arterial hypertension. Chest 2012; 141: 354-362.

9 Sitbon O, Jaïs X, Savale L, et al. Upfront triple combination therapy in pulmonary arterial hypertension: a pilot study. Eur Respir J 2014; 43: 1691-1697.

10 Humbert M, Wagner TO. Rare respiratory diseases are ready for primetime: from Rare Disease Day to the European Reference Networks. Eur Respir J 2017; 49: 1700085. 